\title{
RESPON PERTUMBUHAN BIBIT KAYU KUKU (Pericopsis mooniana (Thw.) Thw) TERHADAP INOKULASI FUNGI MIKORIZA ARBUSKULA LOKAL
}

Growth response of kayu kuku (Pericopsis mooniana (Thw.) Thw) seedling to indigenous arbuscular mycorrhizal fungi inoculation

\author{
Husna $^{1}$, Sri Wilarso $\mathrm{R}^{2}$, Irdika Mansur ${ }^{2}$, dan Cecep Kusmana ${ }^{2}$ \\ ${ }^{1}$ Mahasiswa Program Doktor Prodi Silvikultur Tropika SPs, IPB \\ J1. Lingkar Akademik Kampus IPB Dramaga, Bogor, Indonesia \\ e-mail: husna.faad19@yahoo.com \\ ${ }^{2}$ Departemen Silvikultur Fakultas Kehutanan IPB \\ Jl. Lingkar Akademik Kampus IPB Dramaga, Bogor, Indonesia
}

Tanggal diterima : 5 Mei 2015, Tanggal direvisi : 25 Mei 2015, Disetujui terbit : 16 September 2015

\begin{abstract}
Effectiveness of indigenous arbuscular mycorrhizal fungi (AMF) and the dependence of legumes to AMF application are determined by the compatibility of AMF and the host plant. This study aims to assess the effectiveness of indigenous AMF on growth, biomass and nutrient uptake of 5 months seedling of kayu kuku (Pericopsis mooniana (Thw.) Thw) grown in greenhouse. The six tested indigenous AMF were isolated from four rhizospheres of kayu kuku at Kolaka District: FMA-HA (natural forests Tanggetada, FMA-BJ (Bali Jaya village plantations), FMA-CA (Lamedai Nature Reserve, FMA-Vale (PT. Vale Indonesia Tbk.), and other two rhizospheres from Kendari city: FMAUHO (park area of Halu Oleo University), FMA-KG (urban forest in Southeast Sulawesi Governor's office). As comparison, there were also included a control (without AMF), a mycofer and an isolate from Kendari (kdr03). The study was designed in a randomized block design with 9 treatments and five replications. The results of study showed that in general AMF inoculations could increase the growth and nutrient uptake of the kayu kuku seedling. FMA-KG and FMA-UHO increased height, stem diameter, number of leaves, and root nodules. They also increased total dry weight at $260 \%$ and $281 \%$ above the control. In addition, FMA-KG increased total chlorophyll and nutrient accumulation. Levels of $C$ organic and total $N$ were not significantly affected by AMF treatment. Levels of total $P, K$, $\mathrm{Ca}$ and $\mathrm{Mg}$ of kayu kuku seedling were generally higher in control, but nutrient accumulation was higher in AMF treatment. There was a strong and significant correlation between nutrient accumulation and kayu kuku seedling biomass.
\end{abstract}

Keywords: $\quad$ root nodules, indigenous arbuscular mycorrhizal fungi, growth, kayu kuku, Pericopsis mooniana

\section{ABSTRAK}

Efektivitas fungi mikoriza arbuskula (FMA) lokal dan ketergantungan jenis tanaman legum terhadap aplikasi FMA ditentukan oleh kecocokan jenis FMA dengan tanaman inang. Penelitian ini bertujuan untuk mengkaji efektivitas FMA lokal terhadap pertumbuhan, biomassa dan serapan hara bibit kayu kuku (Pericopsis mooniana (Thw.) Thw.) umur 5 bulan di rumah kaca. FMA lokal yang diuji diisolasi dari empat rizosfer kayu kuku di Kabupaten Kolaka: FMA-HA (hutan alam Tanggetada), FMA-BJ (hutan tanaman Desa Bali Jaya), FMA-CA (Cagar Alam Lamedai), FMA-Vale (PT. Vale Indonesia Tbk.), dan dua rizosfer yang berasal dari Kota Kendari: FMA-UHO (taman kampus Universitas Halu Oleo), FMA-KG (hutan kota kantor Gubernur Sulawesi Tenggara). Perlakuan tanpa FMA (kontrol) dan FMA eksotik (Mycofer) serta isolat dari Kendari (kdr 03) juga digunakan sebagai pembanding. Rancangan percobaan adalah rancangan acak kelompok dengan 9 perlakuan dan 5 ulangan. Secara umum, aplikasi FMA mampu meningkatkan pertumbuhan dan perbaikan status hara tanaman. FMAKG dan FMA-UHO mampu meningkatkan pertumbuhan tinggi, diameter, jumlah daun dan jumlah bintil akar bibit kayu kuku. Kedua FMA ini juga mampu meningkatkan berat kering total bibit kayu kuku masing-masing sebesar $260 \%$ dan $281 \%$ lebih tinggi dibandingkan kontrol. Terdapat peningkatan jumlah klorofil total pada bibit kayu kuku yang diberi perlakuan FMA-KG. Perlakuan 
FMA secara umum tidak memberikan pengaruh yang nyata terhadap kadar $\mathrm{C}$ organik dan $\mathrm{N}$ total. Walaupun kadar $\mathrm{P}$ total, $\mathrm{K}$ total, $\mathrm{Ca}$ total dan $\mathrm{Mg}$ total bibit kayu kuku lebih tinggi pada kontrol, akumulasi hara ditemukan lebih tinggi pada perlakuan FMA. Terdapat hubungan yang kuat dan signifikan antara akumulasi hara dengan biomassa bibit kayu kuku.

Kata kunci : Inokulasi, fungi mikoriza arbuskula lokal, bibit, kayu kuku, Pericopsis mooniana

\section{PENDAHULUAN}

Fungi mikoriza arbuskula (FMA) merupakan kelompok fungi dari filum Glomeromycota (Schüßler and Walker, 2010) yang bersimbiosis dengan sistem perakaran tanaman tingkat tinggi (Smith and Read, 2008) dan ditemukan pada berbagai tipe ekosistem hutan (Delvian, 2003; Yang et al., 2011). Hasil studi keragaman FMA Lokal menunjukkan bahwa ditemukan 15 jenis FMA yang bersimbiosis dengan rizosfer kayu kuku pada daerah sebaran alami dan daerah pengembangan kayu kuku (Husna et al., 2014). FMA yang ditemukan sangat potensial untuk dikembangkan dan perlu dilakukan pengujian tingkat efektivitasnya. Fungi mikoriza arbuskula merupakan salah satu fungi yang efektif dalam perbaikan dan budidaya jenis terancam punah (Sharma et al., 2008; Zubek et al., 2009) dan secara siginifikan dapat mempercepat suksesi dan keberhasilan hidup jenis dalam program konservasi dan rehabilitasi (Zubek et al., 2009; Bothe et al., 2010; Fuchs and Haselwandter, 2004; Fuchs and Haselwandter, 2008; Panwar and Tarafdar,
2006). Namun, peran tersebut sangat dipengaruhi oleh propagul infektif. Propagul FMA terdiri atas akar terinfeksi, spora dan hifa (Smith and Read, 2008). Inokulum FMA yang dikembangkan dari propagul asli sangat disarankan dalam kegiatan budidaya dan restorasi karena lebih efisien, efektif dari segi biaya, adaptif tinggi terhadap kondisi lokal dan tidak berdampak negatif terhadap lingkungan (Maiti et al., 2011). Pemilihan dan produksi FMA yang tepat baik secara kualitas maupun kuantitas merupakan isu penting untuk penerapan FMA. Tahap penting dalam penerapan FMA adalah seleksi isolat fungi efektif yang digunakan sebagai inokulan (Calvente et al., 2004).

$$
\text { Beberapa studi mengenai }
$$
efektivitas FMA telah dilakukan dalam meningkatkan pertumbuhan dan biomasa tanaman serta serapan unsur hara tanaman legum (Giri and Mukerji, 2004; Giri et al., 2005) dan jenis terancam punah (Turjaman et al., 2006; Prayudyaningsih, 2007). Studi aplikasi FMA pada jenis tanaman legum tropis terancam punah kayu kuku (Pericopsis mooniana (Thw.) Thw.) di Indonesia telah dilakukan (Husna, 2010; Iskandar, 2010). Selama ini, sumber FMA 
yang digunakan pada kayu kuku adalah Mycofer dan bukan dari rhizosper kayu kuku. Untuk itu perlu dilakukan penelitian tentang penggunaan jenis-jenis FMA lokal khususnya yang diisolasi dari rizosfer pohon kayu kuku. Penelitian ini dilakukan untuk mengetahui respon pertumbuhan bibit kayu kuku (P. mooniana) terhadap inokulasi fungi mikoriza arbuskula lokal yang diisolasi dari beberapa rizosfer di Sulawesi Tenggara.

\section{BAHAN DAN METODE}

\section{A. Waktu dan tempat}

Pengujian efektivitas FMA lokal dilakukan selama 5 bulan (September 2013 - Februari 2014) di rumah kaca Departemen Silvikultur dan Laboratorium Silvikultur Fakultas Kehutanan IPB. Analisis kimia media semai dan serapan hara dilakukan di Laboratorium Tanah dan Tanaman SEAMEO BIOTROP Bogor.

\section{B. Bahan dan alat}

Bahan yang digunakan dalam penelitian ini adalah benih kayu kuku, tanah dan pasir, polybag $(15 \times 20 \mathrm{~cm})$, air, $\mathrm{KOH}$, $\mathrm{HCl}$, Trypan blue, aquades, inokulum FMA dari hasil trapping dan mycofer, zeolit, bak plastik berukuran $40 \mathrm{x}$ 30 x $15 \mathrm{~cm}$, atonik dan sodium hypochlorite $5 \%$. Alat yang digunakan pada penelitian ini adalah timbangan digital, gunting, alat teknik sentrifugasi, mikroskop compound, penggaris, caliper, dan kamera.

\section{Rancangan percobaan}

Penelitian ini disusun berdasarkan Rancangan Acak Kelompok (RAK), yang terdiri dari 9 perlakuan (Tabel 1).

\section{Tahapan}

\section{Penyemaian benih kayu kuku}

Buah kayu kuku dikoleksi dari pohon induk di Desa Bali Jaya, Kecamatan Lamedai, Kabupaten Kolaka. Pengumpulan dilakukan dengan cara memanjat dari pohon. Buah kayu kuku dikeringanginkan selama 4 hari dan kemudian biji dikeluarkan dari buah secara manual. Sebelum dikecambahkan, perlakuan awal benih berupa pengikiran pada salah satu sisi benih (tepat di bagian kalaza) dan perendaman dengan giberelin 0,05 ppm selama 6 jam. Benih dikecambahkan pada bak plastik berukuran $40 \times 30 \times 15 \mathrm{~cm}$ yang berisi media zeolit steril dengan ukuran $2 \mathrm{~mm}$. Media semai yang akan digunakan pada penelitian ini adalah tanah dan pasir steril (2:1).

\section{Inokulasi FMA}

Fungi mikoriza arbuskula diperoleh dari hasil trapping. Sebelum inokulasi FMA, polybag (ukuran $15 \times 20 \mathrm{~cm}$ ) diisi media tanam $1 \mathrm{~kg}$. Inokulasi FMA diberikan 5 g untuk setiap polybag dan diletakkan dekat akar semai kayu kuku (jenis dan jumlah spora disajikan pada 
Lampiran 1). Semai yang tidak diinokulasi dijadikan sebagai kontrol. Semai dipelihara dan disiram 2 (dua) kali setiap hari pada kondisi rumah kaca dan diamati selama 5 bulan. Gulma dan hama yang menggangu semai dikendalikan setiap hari.
Pengukuran temperatur dan kelembaban rumah kaca dilakukan setiap hari dengan alat hygro thermometer. Pengamatan kolonisasi FMA yang terbentuk mengikuti metode yang dikembangkan Brundrett et al. (1996).

Tabel 1. Perlakuan FMA dan jumlah sampel tanaman yang digunakan dalam penelitian respon pertumbuhan bibit kayu kuku terhadap inokulasi FMA lokal

\begin{tabular}{lccc}
\hline \multicolumn{1}{c}{ Perlakuan } & Ulangan & Unit & $\begin{array}{c}\text { Total } \\
\text { tanaman }\end{array}$ \\
\hline Kontrol & 5 & 5 & 25 \\
FMA-KG (asal hutan kota di kantor Gubernur Sulawesi Tenggara) & 5 & 5 & 25 \\
FMA-UHO (asal taman kampus Universitas Halu Oleo) & 5 & 5 & 25 \\
FMA-Vale (asal PT. Vale Indonesia, Kolaka) & 5 & 5 & 25 \\
FMA-CA (asal Cagar Alam Lamedai) & 5 & 5 & 25 \\
FMA-BJ ( asal hutan tanaman Desa Bali Jaya) & 5 & 5 & 25 \\
FMA-HA (asal Hutan Alam Tanggetada) & 5 & 5 & 25 \\
Mycofer & 5 & 5 & 25 \\
kdr03 (isolat dari Kendari) & 5 & 5 & 25 \\
\hline
\end{tabular}

\section{Parameter yang diamati}

Parameter yang diukur adalah tinggi, diameter, jumlah daun, biomasa tanaman (berat kering tanaman), nisbah pucuk akar (NPA), indeks mutu bibit (IMB), ketergantungan mikoriza, jumlah bintil akar, jumlah spora dan kolonisasi akar. Peubah yang diukur dan didefinisikan disajikan pada Tabel 1.

\section{Analisis Data}

Hasil pengamatan pada setiap satuan amatan akan dianalisis terlebih dahulu dengan analisis sidik ragam (uji F). Apabila hasil uji menunjukkan pengaruh nyata maka akan dilakukan uji beda perlakuan menurut Duncan Multiple Range Test (DMRT) pada taraf 5\%.
III. HASIL DAN PEMBAHASAN

\section{A. Hasil}

\section{Simbiosis FMA}

Akar bibit kayu kuku terkolonisasi FMA baik oleh perlakuan kontrol maupun dengan perlakuan FMA (Tabel 3). Kolonisasi akar oleh FMA tertinggi pada perlakuan FMA-KG dari Kantor Gubernur sebesar 58,7\% diikuti oleh FMA-UHO dari Kampus Universitas Halu Oleo (52,6\%) serta FMA-CA dan FMA Kdr03 masing-masing 51,6\%. Jumlah spora per 50 gram tanah kering terbanyak ditemukan pada perlakuan FMA-KG (50,2 spora) dan terendah pada perlakuan kontrol $(0,6$ spora). Kolonisasi FMA berkorelasi dengan jumlah spora $(\mathrm{r}=0,623, \mathrm{P}<0.001)$. 
Tabel 2. Parameter pertumbuhan dan ketergantungan jenis terhadap FMA

\begin{tabular}{|c|c|}
\hline Parameter bibit kayu kuku & Formula dan definisi \\
\hline Tinggi $(\mathrm{cm})$ & $\begin{array}{l}\text { Pengukuran tinggi dilakukan dengan penggaris, mulai dari pangkal batang } \\
\text { sampai dengan titik tumbuh tertinggi pada jalur batang. }\end{array}$ \\
\hline Diameter (mm) & $\begin{array}{l}\text { Pengukuran dilakukan pada batang setinggi } 1 \mathrm{~cm} \text { di atas media dengan } \\
\text { menggunakan kaliper }\end{array}$ \\
\hline Jumlah daun (helai) & Menghitung pertambahan jumlah daun \\
\hline Nodulasi & jumlah total bintil pada akhir pengamatan \\
\hline Berat Kering Tanaman (gram) & $\begin{array}{l}\text { Bagian bibit dioven pada suhu } 70{ }^{\circ} \mathrm{C} \text { selama } 2 \text { kali } 24 \text { jam kemudian } \\
\text { ditimbang }\end{array}$ \\
\hline Nisbah pucuk akar (NPA) & Perbandingan berat kering bagian pucuk dengan berat kering bagian akar \\
\hline Indeks Mutu Bibit (IMB) & $\begin{array}{l}\text { [Bobot kering pucuk }+ \text { bobot kering akar }] /[\text { (tinggi/diameter })+(\text { bobot kering } \\
\text { pucuk/bobot kering akar)]. Bibit bermutu apabila nilai IMB } \geq 0,09 \text { (Duryea } \\
\text { and Dougherty, 1991) }\end{array}$ \\
\hline Klorofil daun. & $\begin{array}{l}\text { Metode pengujian klorofil daun menggunakan gabungan modifikasi metode } \\
\text { Gross (1991) dan Harborne (1987). Kadar klorofil dihitung menggunakan } \\
\text { rumus: }\end{array}$ \\
\hline & $\begin{array}{ll}- & \text { klorofil A }(\mathrm{mg} / \mathrm{L})=12.7(\text { A.663 })-2.69(\text { A. } 645) \\
- & \text { klorofil B }(\mathrm{mg} / \mathrm{L})=22,9(\text { A.645) }-4,68(\text { A.663) } \\
\text { - } & \text { klorofil total }(\mathrm{mg} / \mathrm{L})=8,02(\text { A. } 663)+20,2(\text { A.645) }\end{array}$ \\
\hline Serapan C, N, P, K, Ca dan Mg & $\begin{array}{l}\text { Kadar } \mathrm{C} \text { organik, } \mathrm{N}, \mathrm{P}, \mathrm{K}, \mathrm{Ca} \text { dan } \mathrm{Mg} \text {. Analisis kadar } \mathrm{C} \text { Organik } \\
\text { menggunakan metode Walkey and Black, kadar } \mathrm{N} \text { Total dengan metode } \\
\text { Kjeldahl serta } \mathrm{P}, \mathrm{K}, \mathrm{Ca} \text {, dan } \mathrm{Mg} \text { menggunakan metode } \mathrm{HNO}_{3}-\mathrm{HClO}_{4} \text { Serapan } \\
\mathrm{C} \text { organik, } \mathrm{N}, \mathrm{P}, \mathrm{K}, \mathrm{Mg} \text { dan } \mathrm{Ca} \text {, diperoleh dengan hasil perkalian kadar } \\
\text { dengan berat kering Jaringan tanaman }\end{array}$ \\
\hline \multicolumn{2}{|l|}{ FMA } \\
\hline $\begin{array}{l}\text { Mycorrhizae inoculation effect } \\
\text { (MIE) }\end{array}$ & $\begin{array}{l}\text { [berat kering tanaman bermikoriza-berat kering tanaman non mikoriza/ berat } \\
\text { kering tanaman bermikoriza] x 100\% (Habte and Manjunath, 1991). }\end{array}$ \\
\hline Kolonisasi FMA & $\begin{array}{l}\text { [ } \Sigma \text { bid pandang bermikoriza/ } \Sigma \text { total bidang pandang yang diamati] x } 100 \% \\
\text { (Brundrett et al., 1996). }\end{array}$ \\
\hline Jumlah spora & $\begin{array}{l}\text { Spora diekstraksi dari } 50 \text { g sampel tanah dengan metode tuang saring basah } \\
\text { (Gerdemann and Nicolson, 1963) dilanjutkan dengan sentrifugasi } \\
\text { supernatan yang diperoleh tambahan 50\% larutan gula (Walker et al., 1982). } \\
\text { Spora FMA yang hasil ekstraksi diamati dan dihitung dibawah mikroskop } \\
\text { dissecting pembesaran 35x. }\end{array}$ \\
\hline
\end{tabular}

Bibit kayu kuku umur 5 bulan memiliki ketergantungan terhadap FMA cukup tinggi sebagaimana ditunjukkan nilai MIE lebih dari 50\%. Bibit yang diinokulasi FMA-KG memiliki nilai MIE tertinggi yakni $71,7 \%$ diikuti FMA-UHO $(69,9 \%)$ dan FMA-Vale $(58,4 \%)$, FMACA (53\%) dan Mycofer (55\%). Sedangkan bibit yang diinokulasi FMA-BJ, FMA-HA dan FMA kdr03 memiliki MIE <50\% (Tabel 3).

\section{Pertumbuhan tanaman}

Tabel 4 menunjukkan bahwa perlakuan FMA berpengaruh sangat nyata terhadap peubah tinggi, diameter, jumlah daun dan jumlah bintil akar bibit kayu kuku. Inokulasi FMA-UHO mampu meningkatkan rata-rata pertambahan tinggi dan diameter bibit dengan peningkatan masing-masing sebesar $139 \%$ dan $37 \%$ terhadap kontrol. Perlakuan FMA-BJ tidak berbeda dengan perlakuan kontrol pada peubah tinggi bibit. Pada peubah diameter, 
pengaruh semua FMA yang diaplikasikan

pada bibit kayu kuku tidak berbeda nyata dengan kontrol kecuali perlakuan FMA-

UHO.

Tabel 3. Pengaruh perlakuan terhadap kolonisasi FMA bibit kayu kuku (P. mooniana) umur 5 bulan

\begin{tabular}{lrrr}
\hline \multicolumn{1}{c}{ Sumber Inokulum FMA } & Kolonisasi $(\%)$ & Jumlah spora & MIE (\%) \\
\hline Kontrol & $2,3 \pm 1,48 \mathrm{e}$ & $0,6 \pm 0,60 \mathrm{e}$ & - \\
KG & $58,7 \pm 7,32 \mathrm{a}$ & $50,2 \pm 2,27 \mathrm{a}$ & $71,7 \pm 6,49 \mathrm{a}$ \\
UHO & $52,6 \pm 4,14 \mathrm{ab}$ & $36,8 \pm 2,67 \mathrm{bc}$ & $69,9 \pm 5,78 \mathrm{a}$ \\
Vale & $49,4 \pm 8,35 \mathrm{bc}$ & $33,6 \pm 1,86 \mathrm{c}$ & $58,4 \pm 4,65 \mathrm{ab}$ \\
CA & $51,6 \pm 8,14 \mathrm{abc}$ & $43,4 \pm 2,42 \mathrm{ab}$ & $53,0 \pm 13,32 \mathrm{abc}$ \\
BJ & $46,9 \pm 5,67 \mathrm{bc}$ & $21,8 \pm 5,10 \mathrm{~d}$ & $31,2 \pm 6,74 \mathrm{~d}$ \\
HA & $38,3 \pm 2,68 \mathrm{~d}$ & $30,6 \pm 1,81 \mathrm{c}$ & $47,3 \pm 11,44 \mathrm{bcd}$ \\
Mycofer & $44,8 \pm 2,18 \mathrm{~cd}$ & $37,4 \pm 1,81 \mathrm{bc}$ & $55,0 \pm 6,64 \mathrm{abc}$ \\
kdr03 & $51,6 \pm 8,31 \mathrm{abc}$ & $37,2 \pm 1,56 \mathrm{bc}$ & $37,8 \pm 2,75 \mathrm{~cd}$ \\
\hline Pr>F & $<.0001$ & $<.0001$ & 0,0008 \\
\hline Ket
\end{tabular}

Keterangan: Nilai rata-rata yang diikuti dengan huruf yang tidak sama pada kolom yang sama berbeda nyata pada taraf 5\% DMRT. MIE = mycorrhizae inoculation effect

Tabel 4. Pengaruh perlakuan terhadap pertumbuhan bibit kayu kuku (P. Mooniana) umur 5 bulan

\begin{tabular}{|c|c|c|c|c|c|}
\hline Inokulum FMA & $\begin{array}{l}\text { Tinggi } \\
(\mathrm{cm})\end{array}$ & Diameter (mm) & Jumlah Daun & $\begin{array}{r}\text { Jum } \\
\text { Bintil }\end{array}$ & \\
\hline Kontrol & $9,32 \pm 0,94$ & $1,71 \pm 0,13$ & $17 \pm 1,53$ & $12 \pm 3,23$ & $\mathrm{~cd}$ \\
\hline $\mathrm{KG}$ & $18,7 \pm 1,31$ & $2,14 \pm 0,10$ & $31 \pm 3,46$ & $47 \pm 7,45$ & $a b$ \\
\hline UHO & $22,3 \pm 1,54$ & $2,34 \pm 0,11$ & $31 \pm 1,99$ & $51 \pm 8,37$ & $\mathrm{a}$ \\
\hline Vale & $13,8 \pm 1,42$ & $2,05 \pm 0,05$ & $24 \pm 0,97$ & $22 \pm 5,57$ & $a b c$ \\
\hline $\mathrm{CA}$ & $16,3 \pm 1,34$ & $1,97 \pm 0,09$ & $23 \pm 1,45$ & $21 \pm 1,59$ & $a b c$ \\
\hline BJ & $12,2 \pm 0,54$ & $1,90 \pm 0,02$ & $23 \pm 0,97$ & $9 \pm 3,01$ & $\mathrm{~d}$ \\
\hline HA & $14,9 \pm 1,31$ & $1,61 \pm 0,19$ & $26 \pm 2,71$ & $26 \pm 4,20$ & $a b c$ \\
\hline Mycofer & $13,8 \pm 0,88$ & $1,83 \pm 0,26$ & $25 \pm 1,02$ & $29 \pm 11,44$ & $a b c$ \\
\hline kdr03 & $17,5 \pm 1,79$ & $1,93 \pm 0,09 \quad \mathrm{abc}$ & $23 \pm 2,40 \quad$ bc & $25 \pm 4,21$ & $a b c$ \\
\hline $\operatorname{Pr}>F$ & $<.0001$ & 0,0186 & 0,0013 & 0,0 & \\
\hline
\end{tabular}

Pertambahan jumlah daun bibit kayu kuku sangat dipengaruhi oleh keberadaan FMA (Tabel 4). FMA-UHO dan FMA-KG mampu meningkatkan pertambahan jumlah daun sebesar $82 \%$ terhadap kontrol. Meskipun demikian, pengaruh FMA-CA, FMA-BJ dan FMA kdr03 tidak berbeda dengan perlakuan kontrol. Jumlah bintil akar tanaman bervariasi antara perlakuan FMA (Gambar 1). Perlakuan FMA-UHO memiliki bintil akar paling banyak dengan peningkatan terhadap kontrol sebesar 325\%, diikuti FMA-KG, FMA-Vale, FMA-CA, FMA-
HA dan FMA kdr03. Jumlah bintil akar terendah ditemukan pada FMA-BJ dan tidak berbeda nyata dengan kontrol.

\section{Biomasa Tanaman}

Hasil analisis keragaman terhadap peubah biomasa bibit kayu kuku menunjukkan bahwa perlakuan FMA berpengaruh signifikan pada seluruh peubah biomasa tanaman (Tabel 5). Hasil uji DMRT menunjukkan bahwa aplikasi FMA lokal seperti FMA-KG dan FMAUHO secara umum berbeda nyata dengan perlakuan lainnya pada seluruh peubah berat kering tanaman, kecuali FMA-UHO 
pada peubah berat kering akar. FMA-KG dan FMA-UHO meningkatkan berat kering total tanaman masing-masing $281 \%$ dan $260 \%$ dibanding kontrol.

\section{Nisbah pucuk akar dan index mutu bibit kayu kuku}

Tabel 6 menunjukkan bahwa nisbah pucuk akar (NPA) bibit kayu kuku umur 5 bulan berkisar antara 2,36-3,68 dengan nilai NPA terrendah ditemukan pada perlakuan kontrol $(2,36)$. Sedangkan index mutu bibit (IMB) dari bibit kayu kuku umur 5 bulan berkisar antara 0,26-0,68. IMB pada bibit yang diberi perlakuan kontrol dan FMA-BJ menunjukkan angka terendah dan secara statistik berbeda nyata dengan perlakuan FMA-KG, FMA-UHO dan FMA-Vale.

\section{Kandungan klorofil daun}

Kandungan klorofil daun kayu kuku umur 5 bulan bervariasi antara perlakuan FMA (Tabel 7). FMA-KG memiliki klorofil a, b dan total lebih tinggi dengan peningkatan $16 \%, 48 \%$ dan $25 \%$ terhadap kontrol. Total klorofil pada perlakuan kontrol tidak berbeda nyata dengan perlakuan lainnya, kecuali dengan perlakuan FMA-KG.

\section{Kadar dan akumulasi unsur hara}

Pengaruh mikoriza terhadap kadar unsur hara $\mathrm{C}, \mathrm{N}, \mathrm{P}, \mathrm{K}, \mathrm{Ca}$ dan $\mathrm{Mg}$ pada jaringan bibit kayu kuku disajikan pada Tabel 8. Kadar C-organik dan N pada jaringan bibit kayu kuku tidak secara nyata dipengaruhi oleh perlakuan FMA dengan kisaran nilai masing-masing 36,5\%-39,4\% dan 1,65\%-1,92\%. Secara umum, bibit kayu kuku pada perlakuan kontrol memiliki kadar $\mathrm{P}, \mathrm{K}, \mathrm{Ca}$ dan $\mathrm{Mg}$ lebih tinggi dibanding perlakuan lainnya. Meskipun demikian FMA-CA tidak berbeda nyata dengan kontrol pada kadar $\mathrm{K}$ dan Mg. Begitupula FMA-HA dan FMA-BJ tidak berbeda nyata dengan kontrol pada kadar $\mathrm{Ca}$ dan $\mathrm{Mg}$.

Secara umum, bibit kayu kuku yang diinokulasi FMA memiliki kemampuan serapan hara yang lebih tinggi dibanding kontrol (Tabel 9). Meskipun demikian, akumulasi hara pada jaringan bibit yang diinokulasi FMA-BJ tidak berbeda nyata dengan kontrol pada semua jenis hara. Pada peubah akumulasi C organik dan $\mathrm{N}$, bibit kayu kuku yang diinokulasi FMA-KG dan FMA-UHO memiliki akumulasi hara terbanyak, dengan peningkatan masing-masing $282 \%$ dan $269 \%$ serta $284 \%$ dan $274 \%$ terhadap kontrol. 

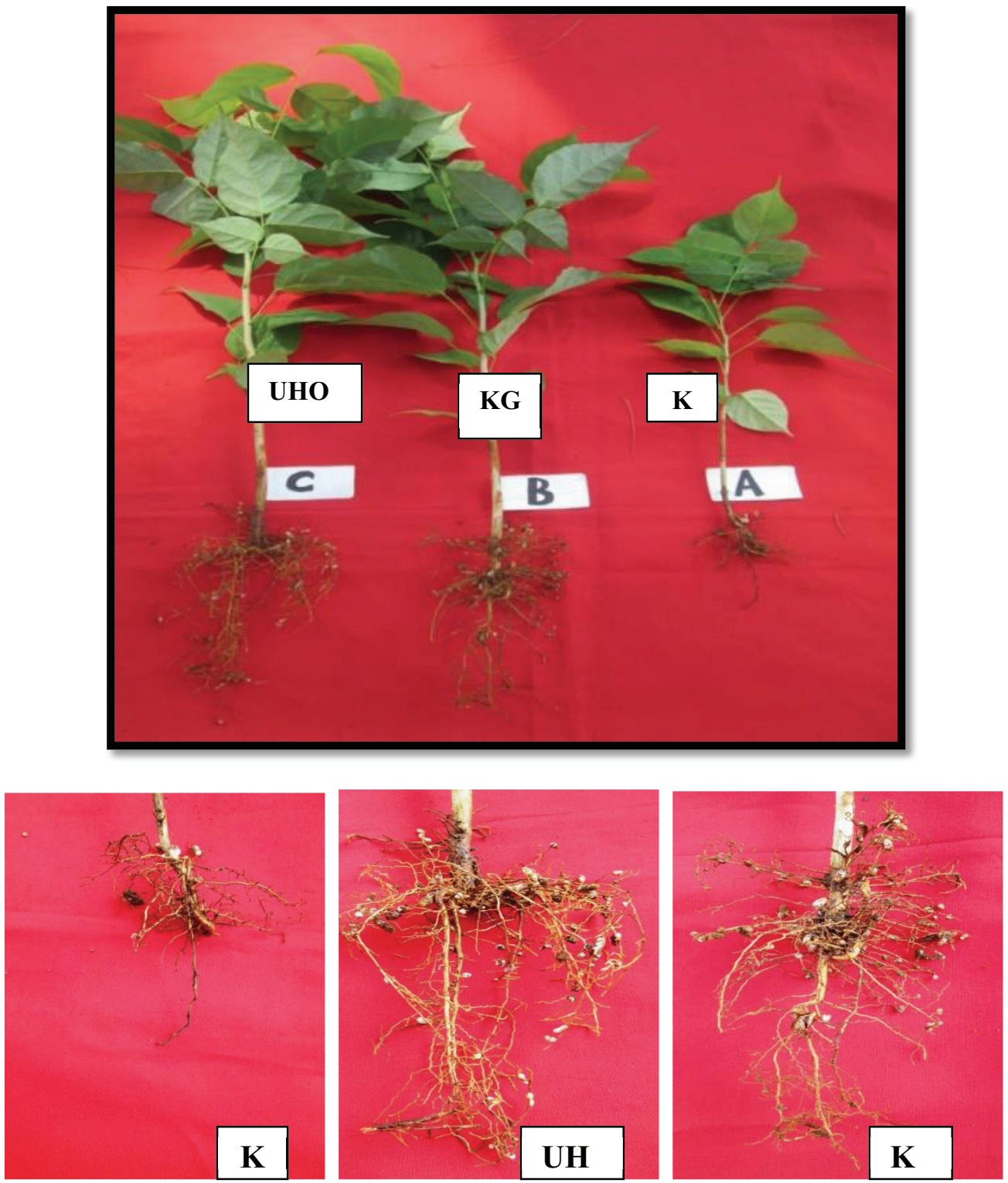

Gambar 1. Kenampakan bintil akar bibit kayu kuku umur 5 bulan di rumah kaca. K (kontrol), KG (FMA dari hutan kota di kantor gubernur) dan UHO (FMA dari taman kampus Universitas Halu Oleo).

Tabel 5. Pengaruh perlakuan terhadap biomasa bibit kayu kuku (P. mooniana) umur 5 bulan

\begin{tabular}{|c|c|c|c|c|c|c|}
\hline Inokulum FMA & \multicolumn{6}{|c|}{ Berat Kering (g) } \\
\hline & \multicolumn{2}{|l|}{ Akar } & \multicolumn{2}{|c|}{ Pucuk } & \multicolumn{2}{|l|}{ Total } \\
\hline Kontrol & $0,47 \pm 0,06$ & d & $1,44 \pm 0,19$ & d & $2,09 \pm 0,30$ & d \\
\hline $\mathrm{KG}$ & $1,69 \pm 0,27$ & $\mathrm{a}$ & $5,85 \pm 0,53$ & $\mathrm{a}$ & $7,98 \pm 0,80$ & $\mathrm{a}$ \\
\hline $\mathrm{UHO}$ & $1,35 \pm 0,27$ & $\mathrm{~b}$ & $5,69 \pm 0,63$ & $\mathrm{a}$ & $7,53 \pm 0,84$ & $\mathrm{a}$ \\
\hline Vale & $1,06 \pm 0,13$ & $\mathrm{c}$ & $3,71 \pm 0,25$ & $\mathrm{~b}$ & $4,99 \pm 0,33$ & $\mathrm{bc}$ \\
\hline $\mathrm{CA}$ & $0,93 \pm 0,14$ & $\mathrm{c}$ & $3,98 \pm 0,52$ & $\mathrm{~b}$ & $5,09 \pm 0,68$ & $\mathrm{~b}$ \\
\hline BJ & $0,48 \pm 0,05$ & d & $2,03 \pm 0,10$ & $\mathrm{~cd}$ & $2,59 \pm 0,16$ & d \\
\hline HA & $1,04 \pm 0,16$ & $\mathrm{c}$ & $2,98 \pm 0,20$ & $\mathrm{bc}$ & $4,23 \pm 0,34$ & $\mathrm{c}$ \\
\hline Mycofer & $1,02 \pm 0,22$ & $\mathrm{c}$ & $3,56 \pm 0,38$ & $\mathrm{~b}$ & $4,86 \pm 0,63$ & bc \\
\hline $\mathrm{kdr03}$ & $1,01 \pm 0,08$ & $\mathrm{c}$ & $4,01 \pm 0,46$ & $\mathrm{~b}$ & $5,46 \pm 0,51$ & $\mathrm{~b}$ \\
\hline $\operatorname{Pr}>F$ & $<.0001$ & & $<.000$ & & $<.000$ & \\
\hline
\end{tabular}

Keterangan: Nilai rata-rata yang diikuti dengan huruf yang tidak sama pada kolom yang sama berbeda nyata pada taraf 5\% DMRT 
Tabel 6. Pengaruh Perlakuan terhadap nisbah pucuk akar (NPA) dan index mutu bibit (IMB) bibit kayu kuku (P. mooniana) umur 5 bulan

\begin{tabular}{lclc}
\hline & Sumber Inokulum FMA & NPA & IMB \\
\hline Kontrol & $2,36 \pm 0,27$ bc & $0,26 \pm 0,03 \mathrm{c}$ \\
KG & $2,88 \pm 0,26$ bc & $0,68 \pm 0,05 \mathrm{a}$ \\
UHO & $3,16 \pm 0,17$ ab & $0,58 \pm 0,05 \mathrm{ab}$ \\
Vale & $3,00 \pm 0,28$ b & $0,52 \pm 0,05 \mathrm{ab}$ \\
CA & $3,68 \pm 0,27$ a & $0,46 \pm 0,09$ abc \\
BJ & $3,68 \pm 0,17$ a & $0,26 \pm 0,02 \mathrm{c}$ \\
HA & $2,56 \pm 0,28$ bc & $0,37 \pm 0,06$ bc \\
Mycofer & $2,92 \pm 0,26$ bc & $0,48 \pm 0,12$ abc \\
kdr03 & $2,82 \pm 0,28$ bc & $0,64 \pm 0,06$ abc \\
\hline Pr>F & 0,0003 & 0,0019 \\
\hline
\end{tabular}

Keterangan: Nilai rata-rata yang diikuti dengan huruf yang tidak sama pada kolom yang sama berbeda nyata pada taraf 5\% DMRT.

Tabel 7. Pengaruh perlakuan terhadap klorofil daun bibit kayu kuku (P. mooniana) berumur 5 bulan

\begin{tabular}{|c|c|c|c|c|c|c|}
\hline \multirow{2}{*}{ Sumber Inokulum FMA } & \multicolumn{6}{|c|}{ Klorofil } \\
\hline & $\mathbf{a}$ & & b & & total & \\
\hline Kontrol & $2,26 \pm 0,08$ & $\mathrm{bc}$ & $1,01 \pm 0,08$ & $\mathrm{bc}$ & $3,27 \pm 0,13$ & bcd \\
\hline $\mathrm{KG}$ & $2,61 \pm 0,14$ & $\mathrm{a}$ & $1,49 \pm 0,10$ & $\mathrm{a}$ & $4,10 \pm 0,24$ & $\mathrm{a}$ \\
\hline UHO & $2,16 \pm 0,14$ & bcde & $0,96 \pm 0,07$ & $\mathrm{c}$ & $3,12 \pm 0,21$ & bcd \\
\hline Vale & $1,95 \pm 0,12$ & cde & $0,92 \pm 0,13$ & $\mathrm{c}$ & $2,67 \pm 0,08$ & $\mathrm{~d}$ \\
\hline $\mathrm{CA}$ & $1,89 \pm 0,15$ & de & $1,03 \pm 0,12$ & $\mathrm{bc}$ & $2,85 \pm 0,26$ & $\mathrm{~cd}$ \\
\hline BJ & $1,85 \pm 0,07$ & e & $1,11 \pm 0,08$ & $\mathrm{bc}$ & $2,78 \pm 0,22$ & $\mathrm{~d}$ \\
\hline HA & $1,99 \pm 0,08$ & bcde & $1,09 \pm 0,06$ & bc & $3,01 \pm 0,15$ & bcd \\
\hline Mycofer & $2,33 \pm 0,02$ & $\mathrm{ab}$ & $1,50 \pm 0,09$ & $\mathrm{a}$ & $3,57 \pm 0,16$ & $a b$ \\
\hline kdr03 & $2,19 \pm 0,07$ & bcd & $1,27 \pm 0,06$ & $a b$ & $3,46 \pm 0,12$ & $\mathrm{bc}$ \\
\hline $\operatorname{Pr}>F$ & \multicolumn{2}{|c|}{0,0003} & \multicolumn{2}{|l|}{$<.0001$} & \multicolumn{2}{|l|}{0,0002} \\
\hline
\end{tabular}

Keterangan : Nilai rata-rata yang diikuti dengan huruf yang tidak sama pada kolom yang sama berbeda nyata pada taraf 5\% DMRT.

Tabel 8. $\quad$ Pengaruh perlakuan terhadap kadar hara bibit kayu kuku (P.mooniana) umur 5 bulan

\begin{tabular}{lcccccc}
\hline Sumber Inokulum & \multicolumn{7}{c}{ Kadar } \\
\cline { 2 - 7 } FMA & $\mathrm{C}(\%)$ & $\mathrm{N}(\%)$ & $\mathrm{P}(\%)$ & $\mathrm{K}(\%)$ & $\mathrm{Ca}(\%)$ & $\mathrm{Mg}(\mathrm{ppm})$ \\
\hline Kontrol & $36,5 \pm 1,25$ & $1,85 \pm 0,8$ & $0,42 \pm 0,04 \mathrm{a}$ & $3,59 \pm 0,20 \mathrm{a}$ & $0,53 \pm 0,02 \mathrm{a}$ & $1102 \pm 35,23 \mathrm{a}$ \\
KG & $37,3 \pm 1,33$ & $1,83 \pm 0,09$ & $0,27 \pm 0,01 \mathrm{bc}$ & $1,21 \pm 0,02 \mathrm{c}$ & $0,32 \pm 0,01 \mathrm{e}$ & $702 \pm 45,48 \mathrm{e}$ \\
UHO & $38,7 \pm 0,85$ & $1,92 \pm 0,08$ & $0,24 \pm 0,01 \mathrm{c}$ & $1,14 \pm 0,04 \mathrm{c}$ & $0,29 \pm 0,01 \mathrm{e}$ & $743 \pm 31,85 \mathrm{de}$ \\
Vale & $38,9 \pm 0,65$ & $1,71 \pm 0,04$ & $0,26 \pm 0,01 \mathrm{bc}$ & $1,56 \pm 0,40 \mathrm{c}$ & $0,31 \pm 0,02 \mathrm{e}$ & $817 \pm 44,65 \mathrm{cde}$ \\
CA & $38,8 \pm 1,08$ & $1,68 \pm 0,09$ & $0,30 \pm 0,00 \mathrm{~b}$ & $2,94 \pm 0,046 \mathrm{ab}$ & $0,38 \pm 0,02 \mathrm{c}$ & $986 \pm 75,65 \mathrm{ab}$ \\
BJ & $38,6 \pm 0,63$ & $1,65 \pm 0,06$ & $0,28 \pm 0,02 \mathrm{bc}$ & $1,56 \pm 0,39 \mathrm{c}$ & $0,48 \pm 0,02 \mathrm{~b}$ & $1115 \pm 39,46 \mathrm{a}$ \\
HA & $38,6 \pm 0,91$ & $1,74 \pm 0,05$ & $0,28 \pm 0,01 \mathrm{bc}$ & $1,56 \pm 0,02 \mathrm{c}$ & $0,49 \pm 0,2 \mathrm{ab}$ & $1105 \pm 42,67 \mathrm{a}$ \\
Mycofer & $39,4 \pm 0,81$ & $1,71 \pm 0,03$ & $0,29 \pm 0,01 \mathrm{bc}$ & $2,33 \pm 0,69 \mathrm{bc}$ & $0,36 \pm 0,02 \mathrm{~cd}$ & $901 \pm 62,66 \mathrm{bc}$ \\
kdr03 & $38,9 \pm 7,19$ & $1,76 \pm 0,33$ & $0,26 \pm 0,01 \mathrm{bc}$ & $1,17 \pm 0,02 \mathrm{c}$ & $0,31 \pm 0,02 \mathrm{e}$ & $882 \pm 29,51 \mathrm{bcd}$ \\
\hline Pr>F & 0,6102 & 0,1437 & $<.0001$ & $<.0001$ & $<.0001$ & $<.0001$ \\
\hline
\end{tabular}

Keterangan: Nilai rata-rata yang diikuti dengan huruf yang tidak sama pada kolom yang sama berbeda nyata pada taraf 5\% DMRT

Akumulasi P pada semua perlakuan FMA menunjukkan angka yang lebih tinggi dibandingkan kontrol, kecuali FMA-BJ. Akumulasi P terbanyak diperoleh pada bibit yang diinokulasi FMA-KG dengan peningkatan 200\% terhadap kontrol. Pada peubah akumulasi $\mathrm{K}$, akumulasi $\mathrm{K}$ pada jaringan bibit yang diinokulasi FMA-CA menunjukkan nilai terbanyak $(0,146 \mathrm{~g})$ dan tidak berbeda nyata dengan FMA-KG dan FMA-HA. Akumulasi $\mathrm{Ca}$ tertinggi ditemukan pada 
jaringan bibit yang diinokulasi FMA-KG

$(0,025 \mathrm{~g})$ dan tidak berbeda nyata dengan

FMA-UHO, FMA-CA dan FMA-HA.

Akumulasi Mg yang lebih tinggi ditemukan pada semua perlakuan bibit bermikoriza, kecuali bibit yang diinokulasi

FMA-BJ dan kontrol. Korelasi antara serapan hara dan berat kering total tanaman menunjukkan hubungan yang positif dan signifikan (Gambar 2).

Tabel 9. $\quad$ Pengaruh perlakuan terhadap serapan unsur hara bibit kayu kuku ( $P$. mooniana) berumur 5 bulan

\begin{tabular}{lcccccc}
\hline \multirow{2}{*}{$\begin{array}{c}\text { Sumber } \\
\text { Inokulum FMA }\end{array}$} & $\mathbf{C}$ & $\mathbf{N}$ & $\mathbf{P}$ & $\mathbf{K}$ & $\mathbf{C a}$ & $\mathbf{M g}$ \\
\cline { 2 - 7 } Kontrol & $0,78 \pm 0,13 \mathrm{c}$ & $0,038 \pm 0,01 \mathrm{c}$ & $0,007 \pm 0,001 \mathrm{~d}$ & $0,076 \pm 0,01 \mathrm{bc}$ & $0,011 \pm 0,001 \mathrm{~d}$ & $0,0023 \pm 0,000 \mathrm{~b}$ \\
KG & $2,98 \pm 0,33 \mathrm{a}$ & $0,146 \pm 0,02 \mathrm{a}$ & $0,021 \pm 0,002 \mathrm{a}$ & $0,094 \pm 0,01 \mathrm{ab}$ & $0,025 \pm 0,002 \mathrm{a}$ & $0,001 \pm 0,001 \mathrm{a}$ \\
UHO & $2,88 \pm 0,27 \mathrm{a}$ & $0,142 \pm 0,01 \mathrm{a}$ & $0,018 \pm 0,002 \mathrm{ab}$ & $0,086 \pm 0,01 \mathrm{bc}$ & $0,022 \pm 0,002 \mathrm{ab}$ & $0,0056 \pm 0,001 \mathrm{a}$ \\
Vale & $1,930,11 \mathrm{~b}$ & $0,085 \pm 0,01 \mathrm{~b}$ & $0,013 \pm 0,000 \mathrm{bc}$ & $0,076 \pm 0,02 \mathrm{bc}$ & $0,015 \pm 0,001 \mathrm{bc}$ & $0,0040 \pm 0,000 \mathrm{a}$ \\
CA & $1,97 \pm 0,25 \mathrm{~b}$ & $0,085 \pm 0,01 \mathrm{~b}$ & $0,016 \pm 0,02 \mathrm{ab}$ & $0,146 \pm 0,03 \mathrm{a}$ & $0,019 \pm 0,003 \mathrm{ab}$ & $0,0049 \pm 0,001 \mathrm{a}$ \\
BJ & $1,000,06 \mathrm{c}$ & $0,042 \pm 0,00 \mathrm{c}$ & $0,007 \pm 0,01 \mathrm{~d}$ & $0,038 \pm 0,01 \mathrm{~d}$ & $0,012 \pm 0,001 \mathrm{~cd}$ & $0,0029 \pm 0,000 \mathrm{~b}$ \\
HA & $1,64 \pm 0,16 \mathrm{~b}$ & $0,073 \pm 0,01 \mathrm{~b}$ & $0,012 \pm 0,01 \mathrm{bc}$ & $0,050 \pm 0,00 \mathrm{~cd}$ & $0,021 \pm 0,002 \mathrm{ab}$ & $0,0047 \pm 0,001 \mathrm{a}$ \\
Mycofer & $1,92 \pm 0,26 \mathrm{~b}$ & $0,082 \pm 0,01 \mathrm{~b}$ & $0,014 \pm 002 \mathrm{ab}$ & $0,096 \pm 0,02 \mathrm{ab}$ & $0,017 \pm 0,002 \mathrm{bc}$ & $0,0042 \pm 0,000 \mathrm{a}$ \\
kdr03 & $2,11 \pm 0,18 \mathrm{ab}$ & $0,095 \pm 0,01 \mathrm{~b}$ & $0,014 \pm 0,01 \mathrm{ab}$ & $0,064 \pm 0,01 \mathrm{bcd}$ & $0,017 \pm 0,001 \mathrm{bc}$ & $0,0049 \pm 0,001 \mathrm{a}$ \\
\hline Pr>F & $<.0001$ & $<.0001$ & 0.0001 & 0,0002 & 0,0001 & $<.0001$ \\
\hline K & & & & & &
\end{tabular}

Keterangan : Nilai rata-rata yang diikuti dengan huruf yang tidak sama pada kolom yang sama berbeda nyata pada taraf 5\% DMRT

\section{B. Pembahasan}

FMA yang diinokulasi mampu membentuk simbiosis dengan sistem perakaran bibit kayu kuku umur 5 bulan. Hal ini dibuktikan dengan ditemukan ornamen atau struktur FMA pada akar tanaman, seperti hifa internal dan eksternal, hifa koil dan vesikula. Strukturstruktur FMA tersebut memiliki peran yang berbeda. Hifa eksternal berperan menyerap unsur hara dan air yang dibutuhkan tanaman (Smith and Read, 2008). Keberadaan struktur FMA tersebut dapat membantu dan memperbaiki status air dan hara serta meningkatkan pertumbuhan tanaman.

Bibit kayu kuku umur 5 bulan membutuhkan kehadiran FMA. Hal ini ditandai dengan nilai ketergantungan terhadap mikoriza (MIE) bibit kayu kuku yang tinggi. Berdasarkan kategori ketergantungan terhadap mikoriza yang dikembangkan oleh Habte and Manajunath (1991) maka bibit kayu kuku termasuk memiliki nilai ketergantungan yang cukup tinggi terhadap FMA. FMA lokal yang diambil dari rizofer di lingkungan Kantor Gubernur, Universitas Halu Oleo, PT. Vale Indonesia, CA Lamedai dan Mycofer memiliki nilai MIE berkisar 50\%-75\% dan moderat untuk perlakuan FMA lainnya. Tingginya nilai MIE pada beberapa FMA lokal mengindikasikan bahwa pertumbuhan dan survival tanaman kayu kuku sangat tergantung pada simbiosisnya dengan FMA. Ketergantungan jenis tanaman yang tinggi terhadap FMA juga dilaporkan pada beberapa jenis pohon 
diantaranya Aquilaria malaccensis dan Aquilaria crasna (Turjaman et al., 2006), Leucaena diversifolia dan L. trichodes (Habte and Manajunath, 1991), Acacia
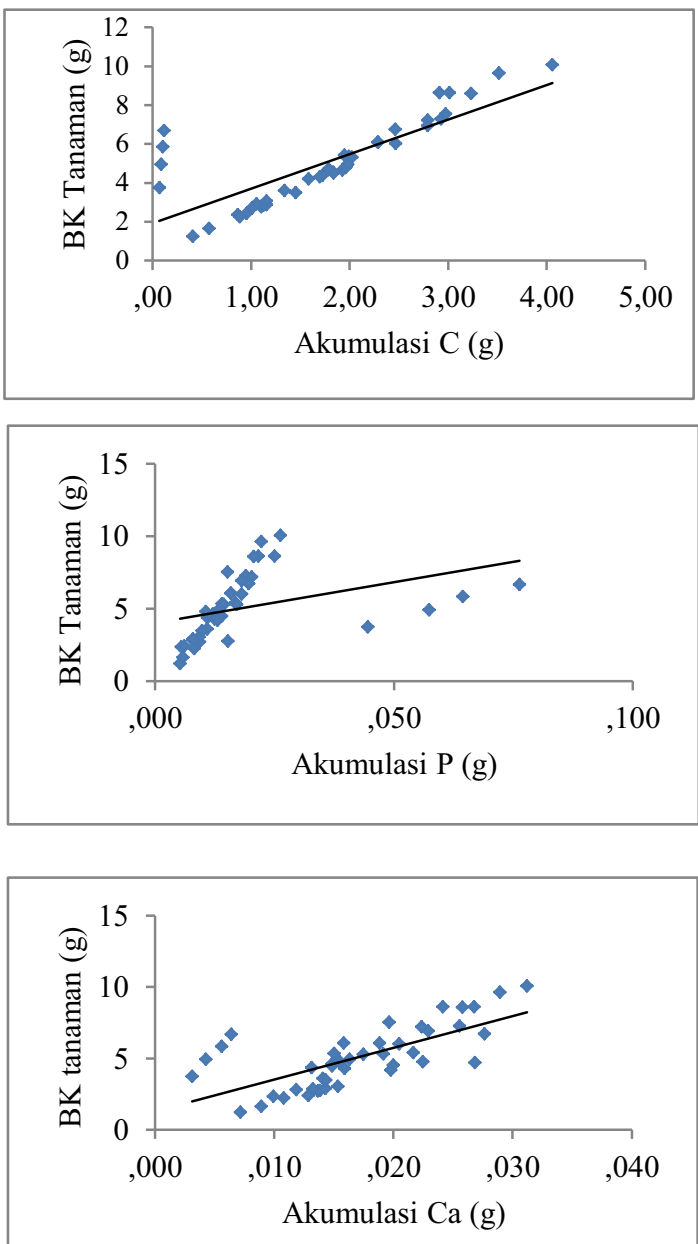

nilotica (Sharma et al., 2001), Acacia mangium (Ghosh and Verma, 2006) dan Albizia saponaria (Tuheteru et al., 2011).
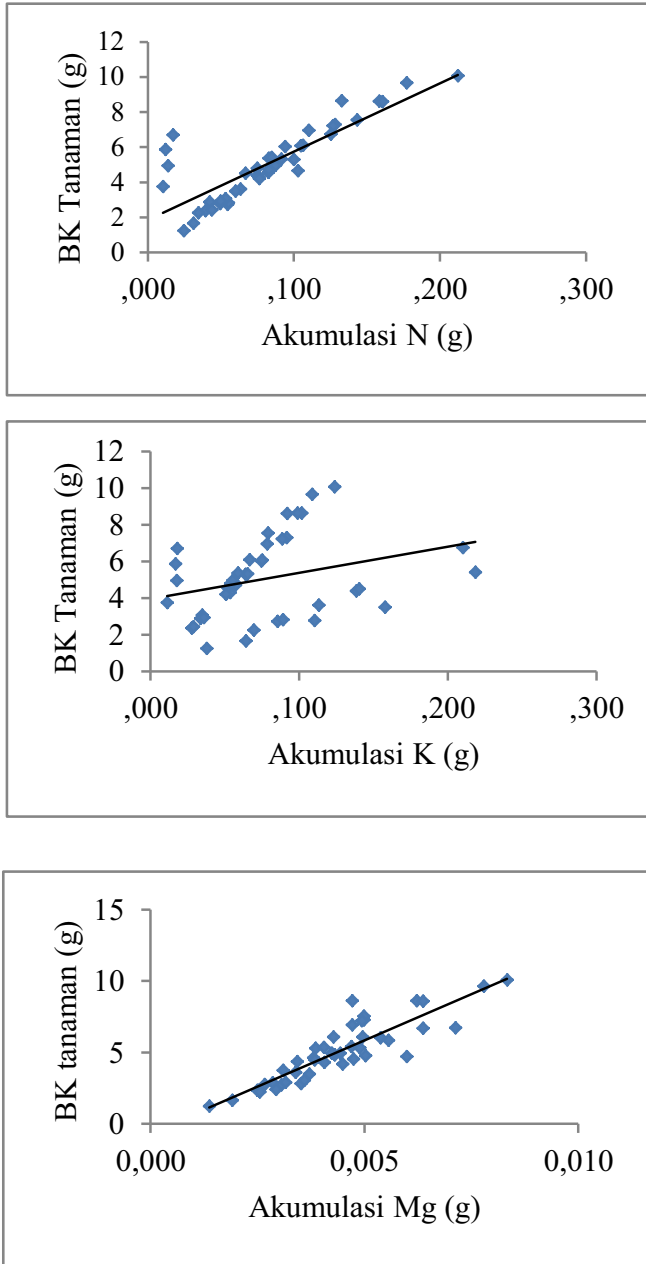

Gambar 2. Korelasi antara akumulasi hara tanaman dengan berat kering bibit kayu kuku (P. mooniana) umur 5 bulan.

Pengaruh kolonisasi FMA dan ketergantungan kayu kuku turut berkontribusi terhadap peningkatan pertumbuhan, biomassa dan akumulasi (serapan) hara bibit kayu kuku umur 5 bulan. Pengaruh signifikan dari masingmasing FMA terhadap pertumbuhan tanaman dan berat kering tanaman sangat bervariasi (Tabel 4 dan Tabel 5). Inokulasi FMA dapat meningkatkan pertumbuhan tinggi bibit sebesar 31\%-139\% terhadap kontrol. Pengaruh FMA terhadap peubah diameter, jumlah daun dan jumlah bintil akar juga sangat bervariasi (Tabel 4). FMA-UHO dari rizosfer di lingkungan Universitas Halu Oleo mampu meningkatkan pertumbuhan tinggi, diameter, jumlah daun dan bintil akar tanaman kayu kuku masing-masing 139\%, $37 \%$, $82 \%$ dan $325 \%$ terhadap kontrol. 
Sedangkan FMA-BJ dari rizosfer di Bali Jaya cenderung memiliki pengaruh yang sama dengan perlakuan tanpa FMA (kontrol). Pertumbuhan tinggi juga erat kaitannya dengan dengan pembentukan daun. Bibit kayu kuku tanpa inokulasi FMA tidak mampu memproduksi daun dalam jumlah banyak (Tabel 4). Peningkatan pertumbuhan dan biomasa tanaman terancam punah yang diinokulasi FMA juga dilaporkan oleh para peneliti sebelumnya. Aplikasi FMA meningkatkan berat kering pucuk jenis terancam punah, seperti Curculigo orchioides Gaertn (Sharma et al., 2008), Plantago atrata dan Senecio umbrosus (Zubek et al., 2009).

Peningkatan pertumbuhan bibit kayu kuku bermikoriza sangat berkait dengan peran FMA dalam perbaikan status nutrisi dan serapan air (Smith and Read, 2008). FMA yang menginfeksi sistem perakaran tanaman inang akan memproduksi hifa secara intensif sehingga tanaman bermikoriza akan mampu meningkatkan kapasitasnya dalam menyerap unsur hara dan air (Brundret et al., 1996; Smith and Read, 2008). Selain itu, peningkatan nodulasi akar oleh FMA (Tabel 4) berkontribusi terhadap peningkatan $\mathrm{N}$ tanaman sehingga dapat mendorong peningkatan pertumbuhan vegetatif tanaman. Peningkatan jumlah bintil akar oleh FMA terkait dengan perbaikan serapan fosfor yang dibutuhkan rhizobium (Javaid, 2010; Muleta, 2010). Pembentukan dan peningkatan jumlah bintil akar kayu kuku oleh FMA juga pernah dilaporkan oleh Iskandar (2010) dan Husna (2010) serta pada jenis pohon lokal Sulawesi Tenggara lainnya seperti Albizia saponaria (Tuheteru et al., 2011) dan Albizia splendens (Budiarti, 2012).

Hasil penelitian ini juga menunjukkan bahwa FMA lokal yang diisolasi dari rizosfer kayu kuku mampu meningkatkan pertumbuhan dan berat kering tanaman dibanding mycofer. FMAUHO dan FMA-KG mampu meningkatkan berat kering total (BKT), tinggi, diameter dan jumlah bintil akar, secara berurutan masing-masing sebesar $55 \%$ dan $64 \%$, $62 \%$ dan $36 \%$, 28\% dan $17 \%, 76 \%$ dan $62 \%$ terhadap mycofer. Meskipun demikian, mycofer masih memiliki pengaruh yang lebih baik dibandingkan FMA-BJ yang berasal dari rizofer hutan tanaman Bali Jaya. Perbedaan efektivitas FMA-UHO dan FMA lainnya diduga berkaitan dengan kompatibilitas jenis FMA dengan kayu kuku. Meskipun demikian, menurut Zubek et al. (2009) jenis FMA asli tidak selalu lebih efisiensi dibanding isolat laboratorium. Pengetahuan efektivitas FMA lokal dan ketergantungan jenis tanaman legum terhadap aplikasi FMA sangat ditentukan oleh kecocokan jenis FMA dan tanaman inang (Widyati et al., 2005; Baar, 2008; 
Estaun et al., 2010). Kemampuan infektif dan efektif FMA-UHO dan FMA-KG sangat tinggi dibanding FMA lainnya. Hal ini diduga karena kedua FMA tersebut memiliki jumlah propagul infektif yang lebih tinggi, yaitu $1,50 \times 10^{4}$ per $100 \mathrm{~g}$ dan $1,09 \times 10^{4}$ per $100 \mathrm{~g}$. Sementara itu, untuk FMA-BJ hanya $0,44 \times 10^{4}$ per $100 \mathrm{~g}$ (Lampiran 1a).

Nisbah pucuk akar (NPA) bibit kayu kuku pada penelitian ini cenderung lebih tinggi pada perlakuan FMA. NPA menggambarkan kelimpahan relatif sumber daya di atas permukaan tanah terhadap sumberdaya bagian perakaran. Pertumbuhan dan kemampuan hidup semai yang terbaik pada umumnya terjadi pada NPA antara 1 dan 3 (Duryea and Brown, 1984). IMB kayu kuku pada penelitian ini telah memenuhi standar IMB $(\geq 0,09)$. IMB tertinggi diperoleh pada perlakuan FMA-KG dan FMA-UHO.

Jumlah klorofil daun pada bibit kayu kuku terbanyak dijumpai pada perlakuan FMA-KG dan mycofer. Klorofil daun berperan penting dalam proses fotosintesis. Hasil penelitian ini menunjukkan bahwa simbiosis FMA dapat mendukung fotosintesis tanaman melalui penyerapan $\mathrm{Mg}$ sebagai komponen penting klrofil daun (Marschner, 1986). Hal ini dikuatkan dengan korelasi antara kadar $\mathrm{Mg}$ total dengan klorofil daun $(\mathrm{r}=0,30$; $\mathrm{P}<0,05)$. Peningkatan kadar klorofil daun oleh FMA juga dilaporkan pada jenis terancam Curculigo orchioides Gaertn (Sharma et al., 2008).

Perlakuan FMA tidak memberikan pengaruh yang nyata pada kadar C-organik dan $\mathrm{N}$ dengan kisaran nilai masing-masing 36,5\%-39,4\% dan 1,65\%-1,92\% (Tabel 8). Secara umum, bibit kayu kuku pada perlakuan kontrol memiliki kadar P, K, Ca dan $\mathrm{Mg}$ lebih tinggi dibanding perlakuan FMA lainnya. Meskipun demikian kontrol tidak berbeda nyata dengan FMA- CA pada konsentrasi $\mathrm{K}$ dan $\mathrm{Mg}$. Kontrol juga tidak berbeda nyata dengan perlakuan FMA-HA dan FMA-BJ pada konsentrasi $\mathrm{Ca}$ dan $\mathrm{Mg}$. Kadar hara yang rendah pada tanaman bermikoriza diduga karena $\mathrm{P}_{2} \mathrm{O}_{5}$ tersedia pada media tanah sangat tinggi (>15 ppm) yakni 45,6 ppm (Lampiran 2). Selain dapat diserap langsung oleh tanaman, kadar $\mathrm{P}$ yang tinggi tersebut dapat berdampak terhadap efektivitas FMA. Kemampuan serapan hara melalui hifa eksternal fungi mikoriza sangat dipengaruhi oleh suplai karbon dari inang. FMA membutuhkan 10\%-20\% hasil fotosintesis bersih untuk pembentukan dan fungsi dari struktur FMA (Bagyaraj, 1992). Powell and Bagyaraj (1984) menyatakan bahwa tanah yang kurang subur akan menurunkan membran phospholipid akar, meningkatkan permiabilitas sel akar sehingga terjadi kebocoran dalam akar yang 
mengakibatkan berkurangnya karbohidrat dan asam amino, peristiwa tersebut akan memacu pembentukan mikoriza. Marschner and Dell (1994) juga menyebutkan bahwa serapan hara tinggi pada tanaman bermikoriza tidak selalu dari serapan dari hifa fungi. Meskipun demikian, bibit kayu kuku yang diinokulasi FMA mengakumulasi hara lebih tinggi dibanding tanpa FMA. Serapan hara sangat dikaitkan dengan biomasa tanaman. Terdapat hubungan positif dan signifikan antara berat kering tanaman dengan serapan hara (Tabel 5).

Akumulasi $\mathrm{C}$ dan $\mathrm{N}$ terbanyak pada perlakuan FMA-KG dan FMA-UHO dengan peningkatan masing-masing sebesar $282 \%$ dan $269 \%$ serta $284 \%$ dan $274 \%$ terhadap kontrol. Akumulasi P tertinggi pada bibit yang diinokulasi FMA dimana bibit yang diinokulasi FMA-KG mengakumulasi $\mathrm{P}$ dalam jumlah banyak $(0,021$ g) dengan peningkatan $200 \%$ terhadap kontrol. Akumulasi Mg tertinggi ditemukan pada bibit bermikoriza kecuali bibit yang diinokulasi FMA-BJ dan kontrol (Tabel 9). Akumulasi hara yang tinggi pada perlakuan mikoriza juga dilaporkan oleh peneliti-peneliti sebelumnya. Kolonisasi FMA oleh Glomus clarum dan $G$. decipiens meningkatkan serapan N dan $\mathrm{P}$ pada jenis Dyera polyphylla (Turjaman et al., 2006) dan lima jenis FMA (Glomus clarum, G. decipiens, Glomus sp. ACA, Entrophospora sp., dan Glomus sp. ZEA) meningkatkan serapan $\mathrm{N}, \mathrm{P}, \mathrm{K}, \mathrm{Ca}$ dan $\mathrm{Mg}$ pucuk Alstonia scholaris (Turjaman et al., 2006).

\section{KESIMPULAN}

Inokulum FMA lokal terbukti cukup efektif untuk meningkatkan pertumbuhan, jumlah bintil akar, biomassa dan serapan hara bibit kayu kuku. Inokulum FMA-KG yang diambil dari rizofer hutan kota di kantor gubernur Sulawesi Tenggara dan FMA-UHO yang diambil dari rizofer taman kampus Universitas Halu Oleo merupakan sumber FMA yang lebih efektif dibanding Mycofer dan kontrol. Bibit kayu kuku memiliki ketergantungan yang cukup tinggi terhadap FMA dengan nilai MIE berkisar antara 50\%-71\%. Meskipun demikian, terdapat sumber FMA tertentu (FMA-BJ dari Bali Jaya) belum berperan optimal dalam mendukung pertumbuhan bibit.

\section{UCAPAN TERIMA KASIH}

Ucapan terima kasih disampaikan kepada Kepala Laboratorium Departemen Silvikultur, Fakultas Kehutanan, Institut Pertanian Bogor atas perizinan yang diberikan untuk melakukan penelitian di rumah kaca dan laboratorium untuk kolonisasi akar. Saudara Faisal Danu 
Tuheteru dan Asriayanti Arief serta Hasanah yang telah membantu dalam penyelesaian penelitian ini dan pihak pengelola jurnal.

\section{DAFTAR PUSTAKA}

Baar, J. (2008). From production to application of arbuscular mycorrhizal fungi in agricultural systems: requirements and needs. In: A. Varma (Ed.). Mycorrhiza (pp. 361-373). New York: Springer.

Bagyaraj, D. J. (1992). Vesicular-Arbuscular Mycorrhiza: Application in agriculture (pp. 359-373). New York (US): Academic Press.

Bothe, H., Turnau, K., \& Regvar, M. (2010). The potential role of arbuscular mycorrhizal fungi in protecting endangered plants and habitats (review). Mycorrhiza, 20, 445457.

Brundrett, M., Bougher, N., Deu, B., Grove, T., \& Majalaczuk. (1996). Working with Mycorrhizas in Forestry and Agriculture (p. 374). Canberra, Australia: Australian Centre for International Agriculture Research.

Budiarti, S. (2012). Nodulasi tanaman legum Albizia Splendens Miq yang diinokulasi dengan fungi mikoriza arbuskula lokal Sulawesi Tenggara (Skripsi). Universitas Halu Oleo, Kendari, Indonesia.

Calvente, R., Cano, C., Ferrol, N., Azcón-Aguilar, C., \& Barea, J.M. (2004). Analysing natural diversity of arbuscular mycorrhizal fungi in olive tree (Olea europaea L.) plantations and assessment of the effectiveness of native fungal isolates as inoculants for commercial cultivars of olive plantlets. Applied Soil Ecology, 26, 11-19.

Delvian. (2003). Keanekaragaman cendawan mikoriza arbuskula (CMA) di hutan pantai dan potensi pemanfaatannya, studi kasus di Hutan Cagar Alam Leuweung Sancang Kabupaten Garut, Jawa Barat (p. 155) (Doctoral Thesis). Institut Pertanian Bogor, Bogor, Indonesia.

Duryea, M. L., \& Brown, G. N. (1984). Seedling physiology and reforestation success. Proceeding of the physiology working group Technical Session (pp. 77-114). Boston: Dr. W. Juck Publishers.
Estaún, V., Cinta, C., \& Camprubí, A. (2010). Effect of differences among crop species and cultivars on the arbuscular mycorrhizal symbiosis (Chapter 13). In: H. Koltai, \& Y. Kapulnik (Eds.). Arbuscular Mycorrhizas: Physiology and Function (pp. 279-296). New York: Springer.

Fuchs, B., \& Haselwandter, K. (2004). Red list plants: colonization by arbuscular mycorrhizal fungi and dark septate endophytes. Mycorrhiza, 14, 277-281.

Fuchs, B., \& Haselwandter, K. (2008). Arbuscular Mycorrhiza of Endangered Plant Species: Potential Impacts on Restoration Strategies. In A. Varma (Ed.). Mycorrhiza (pp. 565-580). Springer.

Ghosh, S., \& Verma, N. K. (2006). Growth and mycorrhizal dependency of Acacia mangium Willd. inoculated with three vesicular arbuscular mycorrhizal fungi in lateritic Soil. New Forests, 31, 75-81.

Giri, B., Kapoor, R., \& Mukerji, K. G. (2005). Effect of the arbuscular mycorrhizae Glomus fasciculatum and $G$. macrocarpum on the growth and nutrient content of Cassia siamea in a Semi-Arid Indian Wasteland Soil. New Forests, 29, 63-73.

Giri, B., \& Mukerji, K. G. ( 2004). Mycorrhizal inoculant alleviates salt stress in Sesbania aegyptiaca and Sesbania grandiflora under field conditions: evidence for reduced sodium and improved magnesium uptake. Mycorrhiza, 14, 307-312.

Habte, M., \& Manjunath, A. (1991). Categories of vesicular-arbuscular mycorrhizal dependency of host species. Mycorrhiza, $1,3-12$.

Husna. (2010). Pertumbuhan bibit kayu kuku (Pericopsis mooniana THW) melalui aplikasi fungi mikoriza arbuskula (FMA) dan ampas sagu pada media tanah bekas tambang nikel (MasterTesis). Universitas Haluoleo, Kendari, Indonesia.

Husna, Budi, S. W., Mansur, I., Kusmana, C., \& Kramadibrata, K. (2014). Fungi mikoriza arbuskula pada rizosfer Pericopsis mooniana (Thw.) di Sulawesi Tenggara. Berita Biologi, 13(3), 263-273.

Iskandar, F. (2010). Peningkatan kualitas bibit kayu kuku (Pericopsis Mooniana Thwaites) yang diberi fungi mikoriza arbuskula dan tepung tulang (Skripsi). Universitas Haluoleo, Kendari, Indonesia. 
Maiti, D., Toppo, N. N., \& Variar, M. (2011). Integration of crop rotation and arbuscular mycorrhiza (AM) inoculum application for enhancing AM activity to improve phosphorus nutrition and yield of upland rice (Oryza sativa L.). Mycorrhiza, 21, 659-667.

Marschner, H. (1986). Mineral nutrition in higher plants (p. 672). London: Academic Press.

Marschner, H., \& Dell, B. (1994). Nutrient uptake in mycorrhizal symbiosis. A. D. Robson, L.K. Aboot, \& N. Malajczuk (Eds.). Netherlands (DE): Kluwer Academic.

Muleta, D. (2010). Legume response to arbuscular Mycorrhizal fungi inoculation in Sustainable Agriculture. In M.S. Khan (Ed.). Microbes for Legume Improvement (pp. 293-324). Springer.

Panwar, J., \& Tarafdar, J. C. (2006). Distribution of three endangered medicinal plant species and their colonization with arbuscular mycorrhizal fungi. Journal of Arid Environments, 65, 337-350.

Powell, C. L. I., \& Bagyaraj, D. J. (1984). VA Mycorrhiza. Florida (US): CRC Press.

Prayudyaningsih, R. (2007). Aplikasi fungi mikoriza arbuskula (FMA) untuk meningkatkan pertumbuhan bibit eboni (Diopyros celebica Bakh.). Prosiding Ekspose Hasil Penelitian Litbang Kehutanan untuk Mendukung Pembangunan Kehutanan Regional, Makassar, 12-13 November 2007. Bogor: Pusat Penelitian dan Pengembangan Hutan dan konservasi Alam., Badan Penelitian dan Pengembangan Hutan dan Konservasi Alam.

Sharma, D., Rupan, K., \& Bhatnagar, A. K. (2008). Arbuscular mycorrhizal (AM) technology for the conservation of Curculigo orchioides Gaertn.: an endangered medicinal herb. World $J$ Microbiol Biotechnol, 24, 395-400.

Sharma, M. P., Bhatia, N. P., \& Adholeya, A. (2001). Mycorrhizal dependency and growth responses of Acacia nilotica and Albizzia lebbeck to inoculation by indigenous AM fungi as influenced by available soil $\mathrm{P}$ levels in a semi-arid Alfisol wasteland. New Forests, 21, 89104.

Schüßler, A., \& Walker, C. (2010). The Glomeromycota: A species list with new families and new genera (p. 56). Kew: The Royal Botanic Garden Kew.
Smith, S. E., \& Read, D. J. (2008). Mycorrhizal symbiosis (3rd ed.) (p. 787). USA (ID): Academic Press.

Tuheteru, F. D., Husna, \& Alimuddin, L. D. (2011). Respon pertumbuhan dan ketergantungan Albizia saponaria (Lour.) Miq terhadap Fungi Mikoriza Arbuskula lokal Sulawesi Tenggara. Biota, 16(2), 252-261.

Turjaman, M., Santoso, E., \& Sumarna, Y. (2006). Arbuscular mycorrhizal fungi increased early growth of gaharu wood of Aquilaria malaccensis and A. crasna under greenhous conditions. Journal of Forestry Research, 3(2), 139-148.

Turjaman, M., Santoso, E., \& Tawaraya, K. (2006). Arbuscular mycorrhizal fungi increased plant growth and nutrient concentrations of milkwood tropical tree species Alstonia scholaris under greenhouse conditions. Journal Forestry Research, 4(2), 61-71.

Turjaman, M., Tamai, Y., Santoso, E., Osaki, M., \& Tawaraya, K. (2006). Arbuscular mycorrhizal fungi incresead early growth of two nontimber forest product species Dyera polyphylla and Aquilaria filaria under greenhouse conditions. Mycorrhiza, $16,459-464$.

Widyati, E., Mansur, I., Kusmana, C., Iswandi, A., \& Santosa, E. (2005). Biodiversity and effectiveness of arbuscular mycorrhizal fungi (AMF) isolated from ex-coal mining area. J. of Forest and Nature Conservation Research, 2(3), 295-302.

Yang, A. N., Liu, L., \& Zhang, N. (2011). The diversity of arbuscular mycorrhizal fungi in the subtropical forest of Huangshan (Yellow Mountain), East-Central china. World J Microbiol Biotechnol. doi: 10.1007/s11274-011-0702-X

Zubek, S., Turnau, K., Tsimilli-Michael, M., \& Strasser, R. J. (2009). Response of endangered plant species to inoculation with arbuscular mycorrhizal fungi and soil bacteria. Mycorrhiza, 19, 113-123. 
Lampiran 1a. Hasil perhitungan uji MPN pada inokulum tanah FMA dari bawah tegakan kayu kuku di enam habitat di Sulawesi Tenggara.

\begin{tabular}{lcc}
\hline \multicolumn{1}{c}{ Habitat } & \multicolumn{2}{c}{ Jumlah propagul infektif (10\%) } \\
\cline { 2 - 3 } & Jumlah/50 $\mathrm{g}$ & $\begin{array}{c}\text { Kisaran jumlah propagul } \\
\text { pada selang kepercayaan 95\% }\end{array}$ \\
\hline Kantor Gubernur & $1,09 \times 10^{4} \mathrm{a}$ & $0,077-5,4 \times 10^{4}$ \\
Universitas Halu Oleo & $1,50 \times 10^{4} \mathrm{a}$ & $0,420-5,4 \times 10^{4}$ \\
PT. Vale Indonesia (Tbk.) & $1,09 \times 10^{4} \mathrm{a}$ & $0,077-5,4 \times 10^{4}$ \\
Cagar Alam Lamedai & $1,09 \times 10^{4} \mathrm{a}$ & $0,077-5,4 \times 10^{4}$ \\
Bali Jaya & $0,44 \times 10^{4} \mathrm{a}$ & $0,077-3,2 \times 10^{4}$ \\
Hutan Alam Tanggetada & $0,66 \times 10^{4} \mathrm{a}$ & $0,059-5,4 \times 10^{4}$ \\
\hline
\end{tabular}

Lampiran 1b. Data jenis dan jumlah spora FMA

\begin{tabular}{|c|c|c|}
\hline Inokulum FMA & Jenis & $\begin{array}{c}\text { Jumlah } \\
\text { spora/50g }\end{array}$ \\
\hline Kantor Gubernur & $\begin{array}{l}\text { Glomus aggregatum, G.boreale, G. canadense, G. halonatum, G. } \\
\text { versiforme, Rhizophagus diaphanous, R. fasciculatus, Sclerocystis } \\
\text { clavispora, Septoglomus constrictum, Claroideoglomus etunicatum, } \\
\text { Scutellospora auriglobosa, dan Racocetra gregaria (12 jenis). }\end{array}$ & 64 \\
\hline Universitas Halu Oleo & $\begin{array}{l}\text { Glomus boreale, G. versiforme, Rhizophagus diaphanous, } \\
\text { Septoglomus constrictum, Claroideoglomus etunicatum, } \\
\text { Scutellospora auriglobosa dan Acaulospora scrobiculata (7 jenis). }\end{array}$ & 58 \\
\hline PT. Vale Indonesia Tbk. & $\begin{array}{l}\text { Glomus boreale, G.canadense, Rhizophagus diaphanous, } \\
\text { Septoglomus constrictum, Claroideoglomus etunicatum } \\
\text { Scutellospora auriglobosa dan Racocetra gregaria (7 jenis). }\end{array}$ & 14 \\
\hline Cagar Alam Lamedai & $\begin{array}{l}\text { Glomus boreale, G. canadense, G.halonatum, G. versiforme, } \\
\text { Septoglomus constrictum, Claroideoglomus etunicatum, Racocetra } \\
\text { gregaria dan Acaulospora delicataa ( } 8 \text { jenis). }\end{array}$ & 16 \\
\hline Bali Jaya & $\begin{array}{l}\text { Glomus boreale, G. versiforme, Rhizophagus diaphanous, } \\
\text { Septoglomus constrictum, Claroideoglomus etunicatum } \\
\text { Scutellospora auriglobosa dan Acaulospora scrobiculata (7 jenis). }\end{array}$ & 22 \\
\hline Hutan Alam Tanggetada & $\begin{array}{l}\text { Glomus canadense, G. Halonatum, G.versiforme, Rhizophagus } \\
\text { diaphanus, Septoglomus constrictum, Claroideoglomus etunicatum, } \\
\text { Scutellospora auriglobosa, Racocetra gregaria dan Ambispora } \\
\text { appendicula (9 jenis). }\end{array}$ & 23 \\
\hline Mycofer & $\begin{array}{l}\text { Glomus etunicatum, G. manihotis, Acaulospora tuberculata dan } \\
\text { Gigaspora margarita ( } 4 \text { jenis). }\end{array}$ & 30 \\
\hline Isolat $\mathrm{Kdr03}$ & Glomus sp dan Acaulospora sp (2 jenis/marga). & 20 \\
\hline
\end{tabular}


Lampiran 2. Sifat kimia dan fisik tanah di lokasi penelitian

\begin{tabular}{|c|c|c|c|c|c|}
\hline No & $\begin{array}{l}\text { Parameter } \\
\text { pengujian* }\end{array}$ & Metoda & Satuan & $\begin{array}{c}\text { Media } \\
\text { sebelum } \\
\text { penelitian }\end{array}$ & $\begin{array}{c}\text { Media } \\
\text { setelah } \\
\text { peneltian }\end{array}$ \\
\hline \multirow[t]{3}{*}{1} & $\mathrm{pH}$ & & & & \\
\hline & $\mathrm{H} 2 \mathrm{O}(1: 1)$ & SNI 03-6787-2002 & & 6,2 & 7,0 \\
\hline & $\mathrm{CaCl} 2(1: 1)$ & & & 6,0 & 6,5 \\
\hline 2 & C Org & SNI 13-4720-1998 (Walkey \& Black) & $\%$ & 0,22 & 0,4 \\
\hline 3 & N Total & SNI 13-4721-1998 (Kjeldahl) & $\%$ & 0,03 & 0,1 \\
\hline 4 & Rasio C/N & & & 7 & 8,2 \\
\hline 5 & $\mathrm{P}_{2} \mathrm{O}_{5}$ tersedia & SL-MU-TT-05 (Bray I/II) & ppm & 45,6 & 50,9 \\
\hline \multicolumn{6}{|c|}{ Kation-kation dapat ditukar } \\
\hline 6 & $\mathrm{Ca}$ & SL-MU-TT07 c (Ekstrak Penyangga NH4Oac & $\mathrm{Cmol}^{(+)} / \mathrm{kg}$ & 4,52 & 8,7 \\
\hline 7 & $\mathrm{Mg}$ & $1,0 \mathrm{~N} \mathrm{pH} \mathrm{7,0}$ & $\mathrm{cmol}^{(+)} / \mathrm{kg}$ & 1,34 & 1,5 \\
\hline 8 & $\mathrm{~K}$ & & $\mathrm{cmol}^{(+)} / \mathrm{kg}$ & 0,92 & 0,9 \\
\hline 9 & $\mathrm{Na}$ & & $\mathrm{cmol}^{(+)} / \mathrm{kg}$ & 1,43 & 1,7 \\
\hline 10 & Total & & $\mathrm{cmol}^{(+)} / \mathrm{kg}$ & 8,21 & 12,8 \\
\hline 11 & KTK & & $\mathrm{cmol}^{(+)} / \mathrm{kg}$ & 6,85 & 10,6 \\
\hline 12 & KB & & $\%$ & 100 & 94,0 \\
\hline \multicolumn{6}{|c|}{$\mathrm{Al}-\mathrm{H}_{\mathrm{dd}}$} \\
\hline 13 & $\mathrm{Al}^{3+}$ & SL-MU-TT-09 (Ekstrak KCl 1N) & $\mathrm{me} / 100 \mathrm{~g}$ & 0,00 & 0,1 \\
\hline 14 & $\mathrm{H}^{+}$ & & $\mathrm{me} / 100 \mathrm{~g}$ & 0,11 & 0,1 \\
\hline \multicolumn{6}{|c|}{ Tekstur 3 Fraksi } \\
\hline 15 & Pasir & SL-MU-TT-10 (pipet) & $\%$ & 35,6 & 32,7 \\
\hline 16 & Debu & & $\%$ & 30,2 & 31,1 \\
\hline 17 & Liat & & $\%$ & 34,2 & 36,2 \\
\hline
\end{tabular}

*Sumber : Services Laboratory SEAMEO BIOTR 